\title{
The Establishment of Musical Aesthetics That "Natural Voice" Is the Most Beautiful Sound
}

\author{
Shalin $\mathrm{Han}^{\mathrm{a}}$, Tao $\mathrm{Yu}^{\mathrm{b}}$ * \\ Art College of Hainan Tropical Ocean University, Hainan Sanya 572022, China \\ ahsl20130214@163.com, *bgeld_geld@163.com \\ *The corresponding author
}

Keywords: Natural sound; Voice; Imitation; Substitutes; Nationality; Cosmopolitan

\begin{abstract}
From the concept perspective of The Establishment of Musical Aesthetics That "Natural Voice" Is the Most Beautiful Sound, this paper systematically and detailedly argues that the aesthetic habits and aesthetic psychological structure of the music from the Chinese people are reflected in the natural aesthetic pursuit of the Chinese nation for thousands of years. This paper also refers to the representative aesthetic theorists in the history of western aesthetics to illustrate that "the natural voice is the traditional aesthetic appreciation of the Chinese nation and the common aesthetic pursuit of mankind". The aesthetics of "the natural voice" of the Chinese nation not only embodies the nationality, but also it is cosmopolitan.
\end{abstract}

\section{Introduction}

"Natural voice "is " natural singing without modification". That "Natural Voice". Is the Most Beautiful Sound is the highest simple unadorned singing that the people had been seeking and advocating since ancient times. It can give people a fresh, simple, and sincere beauty. It is not only the Chinese aesthetic tradition of the voice, but also it is the human common aesthetic and the pursuit, which embodies the cosmopolitan for the aesthetic view of the Chinese nation.

\section{The Aesthetic Discourse of China's Beauty of "Natural Voice," Since Ancient Times}

The natural thing as aesthetic expression in music is to distinguish the musical instruments and voice as different levels of beauty. On the whole, it is the affirmation of the human voice, praise of the voice and to despise the sound of instrumental music. In this regard, the ancient sage provided a lot of discussion for us.

Firstly, the book Rites of Zhou which was created in the Warring States Time is a work describing the bureaucratic establishment and rites. In this book, the chapter Music master, Spring officer, Rites of Zhou says: "Gu shows the poetry...Music masters play instruments at the downside of the lobby". Zhen Silong explains: "As for music, singers are the most important, and instruments are secondary. " The chapter Special effect, Rites says: "Singers are most important which is on the upside, instruments are secondary which are on the downside. The human voice is most valuable. "The 'upside' and 'downside' shows the value and position in aesthetics as well as the spatial position of performers.

Secondly, the famous poet Tao Qian recorded a dialogue between Hengwen and Tao Mengjia in Jin Dynasty Jingu West warring General Mengfu Biography. Wen asks: 'Is liquor good? Why you like it so much.' Jia says:' You don't understand the pleasure of liquor.' Wen asks again: 'When enjoying music, sound from an instrument played by hand is not good as pipe instrument; pipe instrument sound is not good as people's voice. Why so?' Jia answers: 'the more natural the better.' This is a dialogue about singing and dancing girls' performance. It means that instrument played by hands are far away from nature. Pipe instrument sound is a little nearer to nature. While the most natural sound is from the human voice. So in all, we know that human voice and sound is the most beautiful and natural one. That is the source of what the 
scholars in which Taoqian is the representative says: 'hand instrument is not good as pipe instrument; pipe instrument is not good as human sound.

Thirdly, Duan Anjie from Tang Dynasty also describes in Yuefu Zalu: "Singer is the essence of sound. So pipe instrument is better than those plays by hand, and pipe instrument is no better than the human voice." Famous poet Bai Juyi says in Yongyue poetry Willow Twenty Rhyne:" singing is better than pipe sound." This shows that Bai Juyi also agrees with the Music aesthetics essay proposition. Music record, Song history says that "Rites say 'human voice is most valuable; singing performers is upper than instrument players.' 'Human voice is the best from all sound in lobby. Instruments are put on the left and right.

Fourthly, Zhu Quan in Ming Dynasty says in his Ci Lin Xu Zhi: " For singing, the most important thing is being stable. Don't overact... The singer sings as if he is flying happily in the sky. It is natural and not any hinder is there. When listening to it, people feel easy and comfortable.

Lastly, Famous drama theorist Li Yu in Qing Dynasty says in his work Xian Qing Ou Ji. Yin Ji 'vegetable comes first':"For sound, hand instrument is not good as pipe instrument. Pipe instrument is not good as a human voice which is the most natural one. For diet, minced meat is not good as normal meat. Normal meat is not good as the vegetable. As the more natural the better.

So we can see that the value of aesthetics of music from all dynasties is: the most beautiful one is the most natural one. Among the most natural sounds, the human voice is the best. The artificial sound is secondary.

\section{The Importance and Uniqueness of "Language" Determine That the Beauty of Singing Instruments is Irreplaceable}

People's singing organs are called "singing instruments" by music theorist. So, singing instruments have a unique point comparing to other instruments that which is language. All animals and insects are able to come out with all kinds of sound in nature. Birds have a beautiful voice. Instruments could come out with fine music. However, only singing instruments could come out with music that has language sound involves in it. Other instruments could not work this way. So language is a special character of human singing, it expresses emotions and makes it unique." As human beings have aesthetics ability, human singing and singing instrument has greater ability in expressing emotions and aesthetics than any other animal and insects and natural sound.

What worths notice is that the ancient "Instrument sound by hand is lower than pipe instrument. Pipe instrument sound is lower than human sound" has three aspects of thoughts.

First, the "eight sound" of ancient early times music which is Jin, Shi, Si, Zhu, Pao, Tu, Ge and $\mathrm{Mu}$.Except for Jin, the material of other instruments such as Shi, Tu, Ge, Si, Mu, Pao, Zhu, etc are all natural material which grows in nature. Why they come out with a different sound, is that they were made by different material and the process is different. Also, the art of worker is different. Si is string instrument and it counts on material very much as well as manual technique.Zhu is less dependent on material and manual technique. Human voice does not rely on the material at all. Not to mention manual process or change. So here comes "Si is no good than Zhu, Zhu is less than Rou".

Second, the Chinese ancient Jin, Shi, Si, Zhu, Pao, Tu, Ge and $\mathrm{Mu}$ are mostly percussion instrument, pipe instrument and string instrument. Their sound is all brief and crisp. There is a sound description of the Lute in Bai Juyi's long poem Song of Pipa: "Sound of big strings comes like heavy rain. Sound of small strings comes like small talk; It comes sometimes heavy and sometimes light; it comes out like big and small beads dropping into the jade plate. Ancient instrument usually lacks lasting and successive sound. The expressions of emotion and pleasantness, it is not as good as a human voice.

Third, the natural sound is beautiful, because the sound of the natural things contains the feelings of life, and they can resonate with human emotions.

The famous poetry of Tang Dynasty, in "Seeing off Meng Dongye", in this paper described the relationship among nature sounds. "No injustice provokes outcry. The silence of vegetation, the sound of 
wind. The water is silent, the wind down of the Yue Ming, or excited, or the trend also stems, boiling or burning. The stone is silent, or hit the ming. People in the language is also the same, there are those who have to say, the song is also thinking, it has a cry. Where to export for sound, it is not light up! Music also, choose the good fake ming. Gold, stone, bamboo, silk, leather, wood, gourd, soil eight, the good Ming also. The time of day is also the same, choose its good and those who call the Ming ming. Is the birds in spring, summer autumn to thunder, insects, with wind in winter. The four phase push wins, it may not be the light on!" Han Yu stressed that all natural sounds are some natural things excited by some force or borrow the sound; therefore, contains the natural rhythm of life and different emotions in all natural voice. The human voice is the voice of nature, which contains a more intense emotions and emotions.

Until the Song Dynasty, Chinese playing skills of stringed musical instrument making and playing wind instruments have obtained the rapid development of huqin string without the fingerboard and fully show that it can continuously play the characteristics of long melody, flute playing can exhibit graceful melody. They can use bright and rich timbre to imitate the voice and sound of nature, and the instrument has the characteristics of singing. In this case, the people give the different opinion for the concept that the sound of silk strings is not better than the sound of bamboo blowing, the sound of bamboo blowing is not better than the throat of people! The song written by Liu Changcai in the poem takes "it is poor for the hands to be interrupterless, who knows the sound is not better than that of the bamboo" as a question.

However, there is no doubt, the concept that the sound of silk strings is not better than the sound of bamboo blowing, the sound of bamboo blowing is not better than the throat of people! is still restricting people's aesthetic idea of music. For example, poetry from the Song Dynasty Su Dongpo described the beauty of a vertical bamboo flute:" there is a guest playing a vertical bamboo flute with song, it sounds beautiful with a long aftersound, just like resentment and honor, weeping and complaining, just like beautiful dance and nice snake, just like a beauty crying in a lone boat." In the view of Su Shi, the sound beauty of a vertical bamboo flute sound like voice. So, the sentence that just like resentment and honor, weeping and complaining, just like beautiful dance and nice snake, just like a beauty crying in a lone boat is used to describe for that.

\section{The "Voice of Nature" is Not Only the Aesthetic Tradition of Chinese Nation but Also the Common Aesthetic Pursuit of Mankind}

It is worth mentioning that, in the aesthetic thinking of music, different nation in the aesthetic appreciation has many of the same concepts. The "Voice of Nature" is not only the aesthetic tradition of Chinese nation, but also it conforms to the common aesthetic psychology of music among the nations of the world. It can be said that the "Natural Voice" embodied by the Chinese nation embodies its own national character, representing the cosmopolitan of the sound aesthetic.

The person's Throat (refers to the Vocal Cords) is the most Beautiful Sound Instruments. The German poet and music theorist of the 18th century (C.F.D.Schubart, 1739-1791) Schulbart believes that "all musical instruments just imitate songs just like the king sitting on the throne, the instruments around her or him seem his common people kneel in front of him. Voice is a natural sound, and all the other natural sound just look like the distant echo of this sacred sound. People's throat is the first purest and the most outstanding musical instrument, natural singing, which is much better than the world's premier violin. You can sing very purely without any training. You can accurately identify the sound. You will know the first and second degree without study. By their own character they will have got their own style. Therefore the people who have (the primary) clear and rich voice must be a real talented singer." Shure Bart emphasizes the idea of the three aspects here: People's throat is a musical instrument which can make the most beautiful sound. People's voice is better than any objects; natural voice is the most beautiful song; the people who have a clear and rich voice is a real talented singer. Schur Barts' aesthetics thinking of sounds is 
similar to that "the sound of silk strings is not better than the sound of bamboo blowing, the sound of bamboo blowing is not better than the throat of people in the ancient time, running in the same groove.

In people's Songs, the Soul Through its Own Body can make a Sound, Which cannot be Compared by all other Musical Instruments. In the 19th century, German philosopher Hegel's famous philosophy of art is similar to aesthetic point of view in the ancient Chinese music. In Hegel 's Aesthetic Lecture, he discusses the aesthetic principles of his artistic classification. Mr. Zhu Guangqian wrote a brilliant and profound comments in Hegel's Chinese version of "Aesthetics", in the first volume, 108, revealing a secret of Hegel's aesthetic thought: "he believes that the art which is not fettered by the material, it can show the freedom of heart freely and advancedly. From the building to the carvings of pictures to music and poetry, the less the restraint of material is, the more enhanced the concept is, so it is more in line with the concept of art. "

Hegel believes that any sort of classification must be subject to a general principle, ruled by the higher principle. For his aesthetic system, the highest principle is: the unity of the rational content and emotional form, and unity of outside material and the subjective spiritual thought. Specifically, in accordance with the symbolic, classical, romantic type of classification to determine the classification of art type standards. In accordance with this standard, the art is classified as: architecture, sculpture, painting, music and poetry. Hidden ideas in this classification principle is that the relationship between spirit and material and its evolution, the basis of classification, but also it is the direction of the development and change of art form. All kinds of art follow the pattern from depending on the sensitive material to gradually getting rid of the process of the emotional material with low to high development.

"From the beginning of the construction of the plastic arts, the development of artistic categories is the spirit which is constantly breaking away from the objective material form, toward the form of material abandoned. In addition, the expression from of art transforms towards the direction of the material form abandoned from the static fixed form; the permanent nature of space becomes a temporary residence in time; the form of space in the art also give place to a plane. Music is the result of the law of development. The music has abandoned the external form of the material, adopting the way of transmitting sound by air vibration to create art. It can be seen that the music depends on the perceptual material factors less." The banner of philosophy and the spirit of subjectivity from Hagel promoted the creation of the human spirit and the nature of freedom, so he highly praised the" human natural voice", ensuring the aesthetic value of voices. This is why Hagel highly praise the human voice.

"The freest and most perfect instrument is the human voice," Hegel said of the human voice. "It combines the characteristics of the wind and the strings, because the human voice is, on the one hand, a vibrating air column. On the one hand, due to muscles, the human voice sound like a taut string. The voice which can be combined with any instrument is perfect. In addition, the human voice can be heard like the voice of the soul itself, which is the expression of inner life in essence, and it is in direct control of this performance. In all other musical instruments, it is not related to the soul and emotion. In nature, it is an object in the shock. However, in the human voice, the soul can make a sound through its own body.

The Natural Singing as the Performance of Emotion Must Pay Attention To The Beauty Of Art Products And Possesses A High Degree Of Beauty. In the nineteenth century, the famous Russian esthetician Chernyshevsky pointed out: "The original purpose and main purpose of the instrumental music was to be accompanied by singing. We cannot help noticing that no matter how frivolous our tastes are, and no matter how hard we are about the tough and flexible technique. Everyone loves vocality more than instrumental music: at the beginning of the song, we no longer pay attention to the band. The violin is more lovable than all the instruments, because it is closer to the voice of human than all the instruments. "The highest praise for the performer is that they can' hear the sound of human beings in the sound of his instrument', showing that instrumental music is an imitation of vocal music, an appendage and substitute for vocal music. 
In addition, Chernyshevsky also highly praises the aesthetic value of the human voice of nature. He said, "Emotions need to be performed," and "natural singing, as an expression of emotion, is a product of nature rather than that of beauty, with a high degree of beauty. Artificial singing is more painstakingly worked, estimated and decorated by the power from the talented people. Even if the performer's voice is soft and incomparable, which can not compensate for the lack of sincere emotion, and this feeling permeates a simple melody from the folk songs, soaked in the voice which is unfinished training by the vocalist. When singing, he does not want to show off his talent and express his voice and skill.However, he needs to reveal his emotions. The difference between artificial singing and natural sound is similar to that an actor who plays as a happy or sad character and a person who is actually happy or sad. That is to say, the difference between the original manuscript and the transcript and between the reality and the imitating.

It can be said that the Chinese traditional vocal pursuit and the aesthetic thinking of praise of the natural voice and the natural beauty has been resonated and echoed in Chernychevsky's aesthetic thought ! Western aesthetics and music theorists' praise of the "natural human voice" is later than the ancient Chinese musicians for nearly two thousand years, emerged in the great romantic cultural trend. It is just the call to "return to nature" and to "return to the true" from the romantic cultural trend, which makes this aesthetic concept of music from the music theorists of China and the West together. Although the starting point of Shulbart, Hegel and Chernyshevsky's philosophical and musical aesthetics is different from that of ancient Chinese music aesthetics, his full affirmation of the human voice is not as good as that the sound of silk strings is not better than the sound of bamboo blowing, the sound of bamboo blowing is not better than the throat of people.

\section{Summary}

Through the above discussion, it can fully be proved that, , the Chinese people had respected the sound of nature and sound of heaven since ancient times. Nowadays, after the baptism of western vocal music in the past century, the Chinese people have renewed their warm welcome and admiration for the folk songs with "original ecology" in the diversified singing style of the vocal music, which fully shows the "collective unconsciousness" in the minds of the musicians as well as in the context of music appreciation reappear as a conscious consciousness. Chinese traditional vocal music takes "taking the natural voice as beauty, natural pure voice is the most beautiful voice" as concept which is from the nation, recognized and respected by the world.

\section{Acknowledgement}

This research was financially supported by the Humanities and Social Science Research Planning Fund Project of the Ministry of Education in 2012 (No.12YJA751048).

\section{References}

[1] Tielin Jin, Aishu Zou, Tielin Jin Vocal Music Teaching Art, Beijing: People music press, pp.23, 2008.

[2] Shaoyu Guo, Wensheng Wang, Chinese Literary Criticism, Shanghai: Shanghai Classics Publishing House, pp.148, 2001.

[3] Bai Li, After the War the Grace Memory Books With a Stream of Yelang Jiuyou Jiangxia Wei Liang Taishou slaughter, Beijing: Zhong Hua Book Company, 2005.

[4] Zhongde Cai, History of Chinese Music Aesthetics, Beijing: People Music Press, pp.223, 1998. 
[5] Meilin Zhang, The South North Yangzhou Road is Long Say Singing Together -- the Summary of the Seminar on the Training of Vocal Talents in Music Education Major in Colleges and Universities in 2014, Singing World, No2, pp. 56, 2015.

[6] The history of Chinese Music Aesthetics People's Music Press , 2003.

[7] Renya Wang, Research on the Inheritance of Chinese Traditional Music in College Teaching, Jilin Education, No.11,pp.11-12, 2012.

[8] Fafen Zheng, Reflection and Reconstruction of Traditional Music Education in Colleges and Universities in China, Journal of Zaozhuang University, vol.27, No.3, pp.36-38, 2010.

[9] Xuning Li, Reflection on the Integration of Traditional Music Culture in the Vocal Music Teaching in Colleges and Universities, Music Space, No24, pp.148+143, 2014.

[10] Xuerong Cui, The Optimization Strategy of Chinese Traditional Music Culture Teaching from the Perspective of Reception Aesthetics, Huangzhong(Journal of Wuhan Conservatory of Music,China), No.2, pp.136-146, 2012. 